\title{
The Openness of Certain Subfunctors of the Probability Measure Functor and the Topological Properties of Spaces of the Form $F(X) \backslash \bigvee_{\mathrm{F}}(X)$
} Jumayev EE*

Department of Mathematics, National Academy of Sciences of Ukraine, Ukraine

\author{
Abstract \\ In this paper, we consider some geometric topological properties of the functor $\mathrm{P}$ - probabilistic measures and its \\ subfunctors in the category of compacta and continuous mappings into itself.
}

Keywords: Functor; Probability measures; Metrizable compacts; Dirac; C-embedding

\section{Introduction}

It is known that the functor $\mathrm{P}$ probability measures is an open functor of compacts and continuous maps into itself acting in the category comp [1]. In this note we show some subfunctors of the functor $\mathrm{P}$ of probability measures also being open functors. This means that these functors translate open mappings between compacts into open mappings. On the other hand, it is known that for any infinite compactum X space $\mathrm{P}(\mathrm{X})$ homeomorphism to a Hubert cube Q. The question naturally arises in what cases from the homeomorphism of the spaces $\mathrm{F}(\mathrm{X})$ and $\mathrm{F}(\mathrm{Y})$ implies the homeomorphism of compact sets $\mathrm{X}$ and $\mathrm{Y}$, for normal functors $\mathrm{F}$ : Comp $\rightarrow$ Comp. And also in this note it is shown that for a functor $\mathrm{P}_{\mathrm{f}}$ : Comp $\rightarrow$ Comp of homeomorphism $\mathrm{P}_{\mathrm{f}}(\mathrm{X}) \backslash \delta(\mathrm{X})$ and $\mathrm{P}_{\mathrm{f}}(\mathrm{Y}) \backslash \delta(\mathrm{Y})$ implies homeomorphism $\mathrm{X}$ and $\mathrm{Y}$. It is further shown that for a compactum hereditary normality of space is equivalent to metrizability.

\section{Preliminaries}

We recall the definition and some properties of the normality of the covariant functor F: Comp $\rightarrow$ Comp acting in the category of compacta. We say that the functor $\mathrm{F}$ :

1. Saves the empty set the point if $F(\varnothing)=\varnothing$ and $F(\{1\})=\{1\}$ where we denote by $\{\mathrm{k}\}, \mathrm{k} \geq 0$ the set of nonnegative integers $\{0,1, . . \mathrm{k}-1\}$, less than. In this terminology $\{0\}=\varnothing$;

2. Monomorphism if for every (topological) embedding $\mathrm{f}: \mathrm{A}$. $\mathrm{F}(\mathrm{f}): \mathrm{F}(\mathrm{A}) \rightarrow \mathrm{F}(\mathrm{X})$, is an embedding.

3. Epimorphic if for every map $f: X \rightarrow Y$ onto $Y$ the map $\mathrm{F}(\mathrm{t}): \mathrm{F}(\mathrm{X}) \rightarrow \mathrm{F}(\mathrm{Y})$ is also a mapping to;

It preserves intersections if for any family $\left\{A_{\alpha}: \alpha \in A\right\}$ of closed subsets of the compact space $\mathrm{X}$ and the identity embedding $\mathrm{i}_{\alpha}: \mathrm{A}_{a} \rightarrow \mathrm{X}$, the map $F(i): \cap\left\{F\left(A_{\alpha}\right): \alpha \in A\right\} \rightarrow X$, defined by the equality $\mathrm{F}(\mathrm{i})$ $(\alpha)=F\left(i_{\alpha}\right)(\alpha)$, is an embedding for every ;

Saves the preimages if for every map $\mathrm{f}: \mathrm{X} \rightarrow \mathrm{Y}$ and every closed set $A \subset Y$ the map $F\left(\left.f\right|_{f^{-1}(A)}\right)\left(f^{-1}(A)\right) \rightarrow F(A)$ is a homeomorphism;

Preserves the weight if $\omega(\mathrm{F}(\mathrm{X}))=\omega(\mathrm{X})$ for an infinite bicompactum $\mathrm{X}$;

7. It is continuous if for any inverse spectrum $S=\left\{X_{\alpha} ; \pi^{a}: \alpha € A\right\}$ of bicompacta, the homeomorphism is the map $\mathrm{f}: \mathrm{F}(\lim \mathrm{S}) \rightarrow \operatorname{limF}(\mathrm{S})$, which has the limit of the maps $F\left(\pi_{\alpha}\right)$, if $\pi_{\alpha}: \operatorname{limS} \rightarrow X_{\alpha}$ end-to-end projections of the spectrum.

In what follows we assume that all the functors under consideration are monomorphic and preserve intersections. We also assume that all functors preserve non-empty spaces. This restriction is irrelevant, since by this we exclude from consideration only the empty functor, i.e. the functor $F$, which takes every space into an empty set. In fact, let $F(X)=\varnothing$ for some nonempty bicompactum $\mathrm{X}$.

Then $F(X)=F(1)=\varnothing$ by the monomorphism of $F$. Now let $Y$ - be an arbitrary non-empty bicompactum. Consider the constant mapping $\mathrm{f}: \mathrm{Y} \rightarrow 1$. Then $F(f)(F(Y)) \subset F(1)=\varnothing$. Consequently, the space $\mathrm{F}(\mathrm{Y})$ is empty, since it is mapped to an empty set. Thus, we have proved that there exists a unique monomorphic functor preserving non-empty sets.

Let $\mathrm{F}:$ Comp $\rightarrow$ Comp be a functor. We denote by $\mathrm{C}(\mathrm{X}, \mathrm{Y})$ the space of continuous mappings from $\mathrm{X}$ and $\mathrm{Y}$ in a bicompact-open topology. In particular $(\{\mathrm{K}\}, \mathrm{Y})$ is naturally homeomorphism to the $\mathrm{k}$ - power of $\mathrm{Y}^{\mathrm{k}}$ in the space $\mathrm{Y}$. The map $(\xi(0), \ldots, \xi(k-1)) \in Y^{k}$ is mapped to the map.

For the functor $\mathrm{F}$, the bicompactum $\mathrm{X}$ of the natural number $\mathrm{K}$, we define the map $\pi_{\mathrm{F}, \mathrm{X}, \mathrm{k}}: \mathrm{C}(\{\mathrm{k}\}, \mathrm{X}) \times \mathrm{F}(\{\mathrm{k}\}) \rightarrow \mathrm{F}(\mathrm{X})$ by the equality $\pi_{\mathrm{F}, \mathrm{X}, \mathrm{k}}(\xi, \alpha)=\mathrm{F}(\xi)(\alpha)$, where $\xi \in C(\{k\}, X), \alpha \in F(\{k\})$.

When it is clear which functor and which bicompactum $\mathrm{Y}$ we are talking about, we denote the map $\pi_{\mathrm{F}, \mathrm{X}, \mathrm{k}}$ by $\pi_{\mathrm{F}, \mathrm{k}}$ or $\pi_{\mathrm{k}}$.

By the Shchepin theorem [2], the map $\mathrm{F}: \mathrm{C}(\mathrm{Z}, \mathrm{Y}) \rightarrow \mathrm{F}(\mathrm{F}(\mathrm{Z}), \mathrm{F}(\mathrm{Y})$ is continuous for every continuous functor $\mathrm{F}$ and bicompacts $\mathrm{Z}$ and $\mathrm{Y}$.

Therefore takes place.

\section{Proposition 1}

For a continuous functor $\mathrm{F}$, a bicompactum $\mathrm{X}$, and a natural number $\mathrm{k}$, the mapping $\mathrm{F}_{\pi \mathrm{F}, \mathrm{X}, \mathrm{k}}$ is continuous [3].

We define the subfunctor $\mathrm{F}_{\mathrm{k}}(\mathrm{X})$ of the functor $\mathrm{F}$ in the following way: for the compact space $\mathrm{X}$, the space $\mathrm{F}_{\mathrm{k}}(\mathrm{X})$ is the image of the map $\pi_{\mathrm{F}, \mathrm{k}}$, and for the mapping $\mathrm{f}: \mathrm{X} \rightarrow \mathrm{Y}$ the map $\mathrm{F}_{\mathrm{k}}(\mathrm{f})$ is the restriction of the map $F(f)$ to $F_{k}(X)$. From the easily verifiable commutatively

${ }^{*}$ Corresponding author: Jumayev EE, Professor, Department of Mathematics National Academy of Sciences of Ukraine, Ukraine, Tel: 215841282; E-mail: erkinov59@bk.ru

Received November 09, 2018; Accepted December 28, 2019; Published January 04, 2019

Citation: Jumayev EE (2019) The Openness of Certain Subfunctors of the Probability Measure Functor and the Topological Properties of Spaces of the Form $F(X) \backslash \eta_{F}(X)$. J Phys Math 9: 294. doi: 10.4172/2090-0902.1000294

Copyright: ( 2019 Jumayev EE. This is an open-access article distributed unde the terms of the Creative Commons Attribution License, which permits unrestricted use, distribution, and reproduction in any medium, provided the original author and source are credited. 


$$
\begin{gathered}
C(\{k\}) \times F(\{k\}) \stackrel{\bar{f} \times i d}{\rightarrow} C(\{k\}, Y) \times F(\{k\}) \\
\pi_{X, k} \downarrow \\
\quad \downarrow \pi_{X, k} \\
F(X) \stackrel{F(f)}{\rightarrow} F(Y)
\end{gathered}
$$

where $\bar{f}(\xi)=f \circ \xi$, we get the inclusion $F(f)\left(F_{k}(X)\right) \subset F_{k}(Y)$ and, therefore, the functoriality of the construction $\mathrm{F}_{\mathrm{k}}$. A functor $\mathrm{F}$ is called a functor of degree $n$ if $F_{n}(X)=F(X)$ for every bicompact $X$, but $F_{n}$ ${ }_{1}(\mathrm{X}) \neq \mathrm{F}(\mathrm{X})$ for some $\mathrm{X}$.

\section{The Main Part}

For compacta $\mathrm{X}, \mathrm{P}(\mathrm{X})$ denotes spaces of probability measures. It is known that for an infinite compactum $X$, this space $P(X)$ is homeomorphism to a Hilbert cube Q [4]. For a natural number n, denotes the set of all probability measures with at most $\mathrm{n}$ supports. $P_{n}(X)=\{\mu \in P(X):|\operatorname{supp} \mu| \leq n\}$. The compact $\mathrm{P}_{\mathrm{n}}(\mathrm{X})$ is a convex linear combination of Dirac measures of the form:

$$
\mu=m_{1} \delta_{x_{1}}+m_{2} \delta_{x_{2}}+\ldots+m_{n} \delta_{x_{n}}, \sum_{i=1}^{n} m_{i}=1, m_{i} \geq 0, x_{i} \in X,
$$

is the Dirac measure at the point $\mathrm{x}_{\mathrm{i}} . \delta(\mathrm{X})$ denotes the set of all Dirac measures of the compactum X. Recall that the space $P_{f}(X) \subset P(X)$ consists of all probability measures of the form $\mu=\mathrm{m}_{1} \delta_{\mathrm{x} 1}+\mathrm{m}_{2} \delta_{\mathrm{x} 2}+\ldots$ $+\mathrm{m}_{\mathrm{k}} \delta_{\mathrm{xk}}$ with finite carriers, for each of which $m_{i} \geq \frac{k}{k+1}$ for some $\mathrm{i}[4,5]$.

For a natural number $\mathrm{n}$, we put $P_{f, n} \equiv P_{f} \cap P_{n}$ i. we have $P_{f, n}(X)=\left\{\mu \in P_{f}(X):|\operatorname{supp} \mu| \leq n\right\} ; \quad P_{f}^{C} \equiv P_{f} \cap P^{C}, P_{f, n}^{C} \equiv P_{f} \cap P_{n} \cap P^{C}, P_{n}^{C} \equiv P_{n} \cap P^{C}$. For the compactum $\mathrm{X}, \mathrm{P}^{\mathrm{C}}(\mathrm{X})$ denotes the set of all measures $\mu \in P(X)$, the carrier of each of which lies in one from the connected components of the compactum [5].

\section{Definition 1}

A seminormal functor is called retroactively stable if for any compactum the subspace is a retract for the compactum. those. there exists a continuous retraction $r_{n_{F}}^{X}: F(X) \rightarrow \eta_{F}(X)$. On the other hand, an embedding $\mathrm{f}: \mathrm{X} \rightarrow \mathrm{Y}$ is called a coretraction if there exists a retraction $\mathrm{r}: \mathrm{Y} \rightarrow \mathrm{X}$. [3]

\section{Proposition 1}

The mapping $\mathrm{f}: \mathrm{X} \rightarrow \mathrm{Y}$ is a coretraction, if and only if there exists a multiplicative extension operator for $f$.

It is obvious that the following holds

\section{Proposition 1}

A semi-normal functor $\mathrm{F}: \mathrm{Comp} \rightarrow$ Comp retroactively $\mathrm{\eta}_{\mathrm{F}}$ is stable if and only if the embedding is a correction for any $X \in$ Comp .

Obviously, for convex compact sets the functor $\mathrm{P}$ of probability measures is retractively stable [5]. hence, AR-compacta are retractively stable for any seminormal functors $\mathrm{F}$. It was shown $[4,6]$ that the subfunctors $\mathrm{P}_{\mathrm{f}} \mathrm{P}_{\mathrm{fn}}, \mathrm{P}_{\mathrm{f}}^{\mathrm{C}}$ and $\mathrm{P}_{\mathrm{f}}^{\mathrm{C}}$ of the functor $\mathrm{P}$ of probability measures are retractively stable. It follows from the definition of retractively stable functors that the retraction $r_{\eta_{F}}^{X}: F(X) \rightarrow \eta_{F}(X)$ is closed and perfect.

\section{Proposition 3}

If $\mathrm{X}$ is contained in $\mathrm{Y}$, then the Banach space $\mathrm{C}(\mathrm{X})$ admits a linear and multiplicative extension operator in $\mathrm{C}(\mathrm{Y})$ if and only if $\mathrm{X}$ is a retract of the space $\mathrm{Y}$ [7].

\section{Corollary 1}

For any retractively $\mathrm{n}_{\mathrm{F}}$ of a stable functor $\mathrm{F}:$ Comp $\rightarrow$ Comp space $\mathrm{y}_{\mathrm{F}}(\mathrm{X}) \mathrm{C}$ - is embedded in the space $\mathrm{F}(\mathrm{X})$.

If $\mathrm{X}$ is a metrizable compactum, then $\mathrm{X}^{\mathrm{n}} \times \mathrm{F}(\mathrm{n})$ is also a metrizable compactum, and the map $\pi_{\mathrm{F}, \mathrm{X}, \mathrm{n}}: \mathrm{X}^{\mathrm{n}} \times \mathrm{F}(\mathrm{n}) \rightarrow \mathrm{F}(\mathrm{X})$ is perfect. Hence $\mathrm{F}(\mathrm{X})$ is metrizable, where $F$ is a retractive $\eta_{F}$ stable functor of degree $\leq n$. Using the reduced properties of retractively $\eta_{F}$ stable functors of finite degree $\mathrm{y}_{\mathrm{F}}$ and properties of perfect mappings [8]. we can assert.

\section{Theorem 1}

For the compactum $X$ and retractively $\eta_{F}$ of stable functors $F$ of degree $\leq \mathrm{n}$ the following conditions are equivalent:

1) $X$ is metrizable;

2) $F(X)$ is metrizable

\section{Corollary 2}

For the functors $\mathrm{F}=\mathrm{Pf}, \mathrm{Pf}, \mathrm{n}, \mathrm{PCf}, \mathrm{n}$ and $\mathrm{P}_{\mathrm{f}, \mathrm{n}}^{\mathrm{C}}$ the following conditions are equivalent:

1) $X$ is metrizable;

2) $F(X)$ is metrizable

Let Q- be a topological property. We say that the space X has the property outside $\mathrm{Q}$ the set $\mathrm{A}$, in the space $\mathrm{X}$ if the space $\mathrm{X} \backslash \mathrm{A}$ has the property $\mathrm{Q}$, where $A \subset X, A \neq \varnothing$. It is known that the normal $\Delta$ of the compactum $X$ normal outside the diagonal satisfies the first axiom of countability [9].

\section{Theorem 2}

For compact subsets of $\mathrm{X}$ and $\mathrm{Y}$, the spaces $\mathrm{P}_{\mathrm{f}}(\mathrm{X})$ and $\mathrm{P}_{\mathrm{f}}(\mathrm{Y})$ are homeomorphism, respectively, outside the sets $\delta(\mathrm{X})$ and $\delta(\mathrm{Y})$ if and only if $\delta(\mathrm{X})$ and $\delta(\mathrm{Y})$ are homeomorphism.

Evidence. Let $\mathrm{X}$ and $\mathrm{Y}$ be compact sets such that $P_{f}(X) \backslash \delta(X) \cong P_{f}(Y) \backslash \delta(Y)$ are homeomorphism to $\mathrm{h}: \mathrm{P}_{\mathrm{f}}(\mathrm{X}) \backslash \delta(\mathrm{X}) \rightarrow \mathrm{Pf}(\mathrm{Y}) \backslash$ $\delta(\mathrm{Y})$.

$\left.\mathrm{h}: \mathrm{P}_{\mathrm{f}} \mathrm{X}\right) \backslash \delta(\mathrm{X}) \rightarrow \mathrm{Pf}(\mathrm{Y}) \backslash \delta(\mathrm{Y})$ we denote by $\mathrm{h}$ this homeomorphism $\mathrm{h}: \mathrm{P}_{\mathrm{f}}(\mathrm{X}) \backslash \delta(\mathrm{X}) \rightarrow \mathrm{Pf}(\mathrm{Y}) \backslash \delta(\mathrm{Y})$. Now we establish a homeomorphism $h^{\prime}: \delta(X) \rightarrow \delta(Y)$. It is known that for any $\delta_{x} \in \delta(X)$ the preimage of $\left(\mathrm{r}_{\mathrm{f}}^{\mathrm{X}}\right)^{-1}\left(\delta_{\mathrm{x}}\right)$ contains the point $\delta_{\mathrm{x}}$. The homeomorphism $\mathrm{h}$ maps the set $\left(\mathrm{r}_{\mathrm{f}}^{\mathrm{x}}\right)^{-1}\left(\delta_{\mathrm{x}}\right) \backslash \delta_{\mathrm{x}}$ to some set $B_{y} \subset P_{f}(Y) \backslash \delta(Y)$. This set $\mathrm{B}_{\mathrm{y}}$ coincides with the set $\left(\mathrm{r}_{\mathrm{f}}^{\mathrm{Y}}\right)^{-1}\left(\delta_{\mathrm{y}}\right) \backslash \delta_{\mathrm{y}}$ for some $\delta_{y} \in \delta(Y)$. there exists $y \in Y_{\text {such that }}$ $\mathrm{By}=\left(\mathrm{r}_{\mathrm{f}}^{\mathrm{Y}}\right)^{-1}(\delta \mathrm{y}) \backslash \delta \mathrm{y}$. As a result, we put the point $\delta_{x} \in \delta(X)$ into the point $\delta_{y} \in \delta(Y) \cdot h^{\prime}\left(\delta_{x}\right)=\delta_{y}$ by the continuity of the mappings $\mathrm{r}_{\mathrm{f}}^{\mathrm{X}} \mathrm{r}^{\mathrm{Y}}$ and the continuity of the homeomorphism $\mathrm{h}$, the continuity of the map $h^{\prime}: \delta(X) \rightarrow \delta(Y)$. The converse is obvious. Theorem 2 is proved.

Similarly, as Theorem 2, we prove the following for the functors $\mathrm{F}=\mathrm{P}_{\mathrm{f}, \mathrm{n}}, \mathrm{P}_{\mathrm{f}, \mathrm{n}}^{\mathrm{C}}$ and $\mathrm{P}_{\mathrm{f}}^{\mathrm{C}}$

\section{Theorem 3}

For compacta $\mathrm{X}$ and $\mathrm{Y}$, the spaces $\mathrm{F}(\mathrm{X})$ and $\mathrm{F}(\mathrm{Y})$ are homeomorphism, respectively, outside the sets $\mathrm{y}_{\mathrm{F}}(\mathrm{X})$ and $\mathrm{y}_{\mathrm{F}}(\mathrm{Y})$ if and only if $\mathrm{j}_{\mathrm{F}}(\mathrm{X})$ and $\mathrm{j}_{\mathrm{F}}(\mathrm{Y})$ are homeomorphism.

The following is given [5]. 
Citation: Jumayev EE (2019) The Openness of Certain Subfunctors of the Probability Measure Functor and the Topological Properties of Spaces of the Form $F(X) \backslash \bigvee_{F}(X)$. J Phys Math 9: 294. doi: 10.4172/2090-0902.1000294

Page 3 of 3

\section{Theorem 4}

Let $\mathrm{X}$ and $\mathrm{Y}$ be openly generated compacta without points of countable character, and $\mathrm{h}: \mathrm{P}_{\mathrm{n}}(\mathrm{X}) \rightarrow \mathrm{P}_{\mathrm{n}}(\mathrm{Y})$ homeomorphism. Then $\mathrm{h}\left(\mathrm{P}_{\mathrm{k}}(\mathrm{X})\right)=\mathrm{P}_{\mathrm{k}}(\mathrm{Y})$ for any natural $\mathrm{k}<\mathrm{n}$, and a quotient, $\mathrm{X}$ homeomorphism of $\mathrm{Y}$.

Theorem 2 implies the following, which is a generalization of Theorem [5].

\section{Corollary 3}

Let $\mathrm{X}$ and $\mathrm{Y}$ be infinite compacta, and let $\mathrm{h}: \mathrm{P}_{\mathrm{f}, \mathrm{n}}(\mathrm{X}) \rightarrow \mathrm{P}_{\mathrm{f}, \mathrm{n}}(\mathrm{Y})$ homeomorphism. Then $\mathrm{h}\left(\mathrm{P}_{\mathrm{f}, \mathrm{k}}(\mathrm{X})\right)=\mathrm{P}_{\mathrm{f}, \mathrm{k}}(\mathrm{Y})$ for any natural $\mathrm{k}<\mathrm{n}$, in particular, the $\mathrm{X}$ homeomorphism $\mathrm{Y}$.

Recall that $Y \subset X$ is a $\mathrm{C}$-embedded in $\mathrm{X}$ if every continuous real function defined on $\mathrm{Y}$ extends to a continuous function on $\mathrm{X}$ [7].

\section{Theorem 5}

Let $\mathrm{F}: \mathrm{Comp} \rightarrow$ Comp be the normal functor of the $A R(m)$ space in $A R(\mathbb{M})$ space. Then $\mathrm{\eta}_{\mathrm{F}} \mathrm{C}$ - is embedded in $\mathrm{F}(\mathrm{X})$ for any $X \in$ Comp .

Evidence. Let $X \in \operatorname{Comp}$, by the continuity of the functor $\mathrm{F}:$ Comp $\rightarrow$ Comp. The compact $\mathrm{y}_{\mathrm{F}}(\mathrm{X})$ is embedded in $\mathrm{F}(\mathrm{X})$. We consider a continuous function $\mathrm{f}: \mathrm{X} \rightarrow \mathrm{R}$ be a real line. The map $\mathrm{F}(\mathrm{f}) \mathrm{F}(\mathrm{X}) \rightarrow \mathrm{F}(\mathrm{R})$ is also continuous. Since $\mathrm{F}$ preserves $A R(\mathbb{m})$ spaces, there exists a retraction $\mathrm{rRf}: \mathrm{F}(\mathrm{R}) \rightarrow \mathrm{R}$. The required continuous extensions are compositions of the map $\mathrm{F}(\mathrm{f})$ and the retraction $\mathrm{r}_{\mathrm{F}}^{\mathrm{R}}$. those. $\bar{f}=r_{F}^{R} \circ F(f): F(X) \rightarrow R$ theorem 4 is proved.

\section{References}

1. Ditor S, Eifler L (1972) Some open mapping theorems for measures. Trans Amer Math Soc 164: 163-172.

2. Schepin EV (1981) Functors and uncountable powers of compact sets. Uspekh mat nauk 36: 3-62.

3. Fedorchuk VV, Filippov VV (1988) General topology. Basic constructions. M.Iz-v MSU p: 252.

4. Zhuraev TF (1989) Some geometric properties of the subfunctors of the functor $\mathrm{P}$ of probability measures. The manuscript was deposited at VINITI ANSSSR, July 5, 1989. No. 4471-B89.

5. Fedorchuk VV (1991) Probabilistic measures in topology. Uspekh mat nauk 46: 41-80.

6. Zhuraev TF (2017) On the properties of certain compact sets of the form $F(X)$. Uzbek mat zhurnal 1: 1-10.

7. Yoshizawa $\mathrm{H}$ (1944) On simultaneous extension of continuous functions. Proc Imp Acad Tokyo 20: 653-654.

8. Engelking R (1986) General topology. M Mir p: 752.

9. Arhangelskie AV, Kombarov AP (1990) On-normal spaces. Top Appl 35: 121126. 